\title{
Multi-Loci Sequence Typing (MLST) for Two Lacto-Acid Bacteria (LAB) Species: Pediococcus parvulus and P. damnosus
}

\author{
Gautier Calmin · Francois Lefort - Lassaad Belbahri
}

Published online: 10 June 2008

(C) Humana Press 2008

\begin{abstract}
The control of wine microbial population during and beyond fermentation is of huge importance for wine quality. Lactic acid bacteria (LAB) in wine are responsible for malolactic fermentation (MLF) which can be desired in some cases and undesirable in others. Some LAB do not perform MLF and their uncontrolled growth could contribute to severe wine spoilage such as undesired flavours. Their identification and detection is considered crucial for numerous biotechnological applications in food fermentations, where, through acidification and secretion of bacteriocins, they contribute to reduce food spoilage and growth of pathogenic microorganisms. LAB have traditionally been classified using morphological or biochemical features. Primary isolation, biochemical identification and phenotypic analysis are laborious, time consuming and inaccurate and often lead to misidentification within some genera such as Pediococcus. Molecular identification based on suitable marker genes could be an attractive alternative to conventional morphological and biochemical methods. We assessed here the applicability of four housekeeping genes $r e c A, r p l B, p y r G$ and $l e u S$ in combination with the mle gene in multi-loci sequence typing (MLST) of Pediococcus parvulus and Pediococcus damnosus. Sequencing and comparative analysis of sequence data were performed on 19 strains collected during wine fermentation. A combination of these five marker genes allowed for a clear differentiation of the strains analysed, indicating their applicability in molecular typing. Analysis of the observed
\end{abstract}

G. Calmin · F. Lefort · L. Belbahri ( $₫)$

Plants and Pathogens Group, Research Institute Earth Nature and Landscape, School of Engineering of Lullier, University of Applied Sciences of Western Switzerland, 150 Route de Presinge, 1254 Jussy, Switzerland

e-mail: lassaad.belbahri@hesge.ch nucleotide polymorphisms allowed designing highly discriminative primers for a multi-loci sequence typing (MLST) method that proved successful in detecting a particular isolate or sequence type of $P$. parvulus when using either conventional PCR or Real Time PCR.

Keywords Lacto-acid bacteria $\cdot$ Multi-loci sequence typing · Pediococcus parvulus · Pediococcus damnosus . PCR - Real time PCR
Abbreviations
API Appareillage et procédé d'identification
LAB Lactic acid bacteria
MLF Malolactic fermentation
MLST Multi-loci sequence typing
PCR Polymerase chain reaction

\section{Introduction}

Lactic acid bacteria (LAB) are among the principal bacteria present during the process of wine making [1, 2]. They are believed to be essential to the quality of many fermented beverages [3]. During wine fermentation, LAB may play dual roles as the main effectors of the malolactic fermentation (MLF) [4] or as wine spoilage agents under certain conditions. Oenococcus oeni is considered as the main LAB species during MLF [5]. LAB such as Pediococcus spp. might lead to different alterations of wine quality through production of exopolysaccharides [6], acetic acid [7] and biogenic amine [8]. The control of wine population during and beyond fermentation is therefore of huge importance for wine quality, and the identification and detection of $\mathrm{LAB}$ is considered crucial for wine 
fermentation as well as for many food fermentations processes involving LAB [9-11].

Established methodologies, routinely used for assessing the evolution of LAB populations, rely on plate counting, morphological descriptors and phenotypic methods based on biochemical systems such as $\mathrm{API}^{\circledR}$ (API, appareillage et procédé d'identification) by Biomérieux (Lyon, France) and phenotypic arrays (Biolog, Hayward, CA, USA) [12, 13]. These methods are strongly dependent of the physiological state of the bacteria, are time consuming and, due to the very slow growth of these $\mathrm{LAB}$ bacteria on synthetic media (up to 20 days), yield delayed results. As a consequence, for instance, misidentification within the genus Pediococcus is common [13]. Alternative molecular LAB typing methods are being developed in several laboratories $[9,10,14-16]$, aiming for higher sensitivity and specificity and better reproducibility. Multi-loci sequence typing (MLST) is one of the preferred methods in molecular typing of LAB and has been applied successfully to Lactococcus casei, Oenococcus oeni, Lactobacillus plantarum and Pediococcus acidilactici [17-20]. The existing MLST schemes were based on housekeeping genes.

Phylogenetic relationships of LAB bacteria are most commonly based on the variability in their ribosomal RNA genes [21, 22]. However, for the classification of closely related species and subspecies, rRNA genes are too conserved and alternative marker genes exhibiting greater differences between species are required [9, 23]. As an alternative, protein encoding gene sequences have been applied for the classification of LAB bacteria $[9,10]$. The mle gene, encoding the malolactic enzyme, has been shown to reflect the phylogenetic position of $\mathrm{LAB}$ cocci [23], with a better phylogenetic resolution than with the 16S rRNA gene.

The objective of the present study was to perform a comparative sequence analysis of relevant marker genes and to exploit the obtained information for developing a DNA-based assay for isolate identification, which could replace traditional morphological identification of the species Pediococcus parvulus and Pediococcus damnosus. The desired method to develop would be reproducible, quick, cheap, relatively free of personnel error and would generate results not only fully compatible with traditional identification schemes but offering a possibility of between strains identification. A multi-loci sequence typing method (including the malolactic fermentation gene) was developed as a modification of the MLST method of Maiden et al. [24] and tested against 19 P. parvulus and $P$. damnosus strains collected during a batch fermentation experiment. In a second step a set of highly discriminative primer pairs was designed for discriminating two P. parvulus strains Bpe 149 and Bpe 184 and proved to be unambiguously effective in detecting a single sequence type (ST) of $P$. parvulus.

\section{Materials and Methods}

Bacterial Strains and Culture Method

Pediococcus strains used in this study are listed in Table 1. Pediococcus strains were obtained from DSMZ (German Resource Centre for Biological Material) or isolated from wine during fermentation at the School of Engineering of Changins. Strains were grown aerobically in MRS vegitone medium (Sigma, Basel, Switzerland) according to manufacturer recommendations at $28^{\circ} \mathrm{C}$. All the strains listed in Table 1 have been checked morphologically and by $16 \mathrm{~S}$ ribosomal DNA sequencing (see below).

\section{Genomic DNA Extraction}

Cells from 5-7 days old cultures were harvested and chromosomal DNA for the polymerase chain reaction (PCR) was prepared by using the UltraClean ${ }^{\mathrm{TM}}$ Microbial DNA Isolation kit (MO BIO Laboratories, Inc., St Quentinen-Yvelines, France) according to the manufacturer's instructions. Quality was checked by visualization under UV light following electrophoresis in $2 \%$ agarose. Concentrations were determined with a NanoDrop ND-1000 UV spectrophotometer (Witec AG, Lucerne, Switzerland).

Table 1 Origin and allelic profiles of the 19 P.parvulus and $P$. damnosus strains analysed

\begin{tabular}{|c|c|c|c|c|c|c|c|c|}
\hline \multirow[t]{2}{*}{ Species } & \multirow[t]{2}{*}{ Strain } & \multirow[t]{2}{*}{$\mathrm{ST}$} & \multicolumn{5}{|c|}{ Allele } & \multirow[t]{2}{*}{ Source } \\
\hline & & & leuS & pyrG & recA & rplB & mle & \\
\hline \multirow[t]{8}{*}{ P. parvulus } & Bpe 165 & 1 & 1 & 1 & 1 & 1 & 1 & EIC \\
\hline & Bpe 207 & 1 & 1 & 1 & 1 & 1 & 1 & EIC \\
\hline & Bpe 290 & 1 & 1 & 1 & 1 & 1 & 1 & EIC \\
\hline & Bpe 149 & 2 & 1 & 1 & 2 & 1 & 1 & EIC \\
\hline & Bpe 184 & 3 & 1 & 2 & 3 & 1 & 1 & EIC \\
\hline & Bpe 301 & 3 & 1 & 2 & 3 & 1 & 1 & EIC \\
\hline & Bpe 299 & 4 & 1 & 3 & 4 & 2 & 2 & EIC \\
\hline & $\begin{array}{l}\text { CBS } \\
20332\end{array}$ & 4 & 1 & 3 & 4 & 2 & 2 & DSMZ \\
\hline \multirow[t]{11}{*}{ P. damnosus } & Bpe 202 & 1 & 1 & 1 & 1 & 1 & 1 & EIC \\
\hline & Bpe 230 & 1 & 1 & 1 & 1 & 1 & 1 & EIC \\
\hline & Bpe 238 & 1 & 1 & 1 & 1 & 1 & 1 & EIC \\
\hline & Bpe 283 & 1 & 1 & 1 & 1 & 1 & 1 & EIC \\
\hline & Bpe 243 & 1 & 1 & 1 & 1 & 1 & 1 & EIC \\
\hline & Bpe 260 & 1 & 1 & 1 & 1 & 1 & 1 & EIC \\
\hline & Bpe 226 & 2 & 2 & 1 & 1 & 1 & 1 & EIC \\
\hline & Bpe 233 & 2 & 2 & 1 & 1 & 1 & 1 & EIC \\
\hline & Bpe 263 & 2 & 2 & 1 & 1 & 1 & 1 & EIC \\
\hline & Bpe 294 & 3 & 3 & 1 & 1 & 2 & 2 & EIC \\
\hline & $\begin{array}{l}\text { CBS } \\
20331\end{array}$ & 3 & 3 & 1 & 1 & 2 & 2 & DSMZ \\
\hline
\end{tabular}




\section{S rDNA PCR Amplification}

16S rDNA amplification of bacterial samples was carried out using the previously described primers fd1 and rp2 [25]. The reaction mixture contained $1 \times$ PCR buffer $(75 \mathrm{~mm}$ Tris$\mathrm{HCl}$ (pH 9.0), $\left.50 \mathrm{mM} \mathrm{KCl}, 20 \mathrm{mM}\left(\mathrm{NH}_{4}\right)_{2} \mathrm{SO}_{4}\right), 0.1 \mathrm{mM}$ dNTPs, $0.25 \mu \mathrm{M}$ of each primer, $1.5 \mathrm{mM} \mathrm{MgCl}_{2}, 1 \mathrm{U}$ of Taq polymerase (Biotools, Spain) and $1 \mathrm{ng}$ of bacterial DNA in a total volume of $50 \mu \mathrm{l}$. PCR conditions included an initial denaturation step of $95^{\circ} \mathrm{C}$ for 2 min followed by 35 cycles of $95^{\circ} \mathrm{C}(20 \mathrm{~s}), 55^{\circ} \mathrm{C}(30 \mathrm{~s})$ and $72^{\circ} \mathrm{C}(2 \mathrm{~min})$ terminated with a final $20 \mathrm{~min}$ chain elongation step.

Amplification with Universal Primers for Other Genes

PCR amplifications of the 16S-23S spacer gene (Jensen et al. 1993), the RNA polymerase $r p o B$ gene and the fusA, gyrB, ileS, lepA, pyrG, recA, recG were carried out with the respective primers [9] and degenerated primers [26]. Not all the strains amplified with these so-called universal primers, which implied redesigning primers specific of the Pediococcus genus. This was achieved on the basis of obtained sequences for some of these genes and of GenBank deposited sequences (NCBI, Bethesda, USA).

Design of Pediococcus spp. Specific Primers and PCR Amplification

In particular, specific primers were designed for the recA, $r p l B$, pyrG, leuS genes with the constraint to display the same annealing temperature range. PCR amplification of recA, rplB, pyrG, leuS and mle from chromosomal DNA was performed by using the respective PCR primers (Table 2). For each target, PCR reactions of $50 \mu$ volume each, consisting of $1 \times$ PCR buffer $(75 \mathrm{mM}$ Tris $-\mathrm{HCl}(\mathrm{pH}$ 9.0), $\left.50 \mathrm{mM} \mathrm{KCl}, 20 \mathrm{mM}\left(\mathrm{NH}_{4}\right)_{2} \mathrm{SO}_{4}\right), 0.1 \mathrm{mM}$ dNTPs, $0.25 \mathrm{mM}$ of both primers, $1.5 \mathrm{mM} \mathrm{MgCl}_{2}, 1 \mathrm{U}$ of Taq Polymerase (Biotools, Madrid, Spain),1 ng genomic DNA as template and $1 \mathrm{U}$ of Taq polymerase (Invitrogen, Switzerland), were performed in a Master Gradient thermocycler (Eppendorf, Hamburg, Germany) according to the following amplification programme: an initial denaturation step of $95^{\circ} \mathrm{C}$ for $5 \mathrm{~min}$ followed by 39 cycles including denaturation for $60 \mathrm{~s}$ at $94^{\circ} \mathrm{C}$, annealing for $60 \mathrm{~s}$ at $55^{\circ} \mathrm{C}$ and extension for $1 \mathrm{~min}$ at $72^{\circ} \mathrm{C}$. Amplification was terminated by a final extension step of $10 \mathrm{~min}$ at $72^{\circ} \mathrm{C}$. Amplicons were checked by gel electrophoresis as previously described.

\section{DNA Sequencing}

For DNA sequencing, PCR products of $16 \mathrm{~S}$ rDNA, recA, $r p l B$, pyrG, leuS and mle genes were purified using the MiniElute PCR Purification Kit (Qiagen, Basel, Switzerland), according to manufacturer's specifications. Quantity and quality were checked as described above for DNA extraction and used as templates in sequencing reactions. Bidirectional sequencing of recA, rplB, pyrG, leuS and mle genes was performed at Microsynth AG (Balgach, Switzerland) by using the respective primer pair used for PCR amplification (Table 2) as sense and antisense sequencing primers. All bacterial DNA samples were sequenced twice and a consensus sequence was created from the duplicates. All DNA sequences have been deposited in GenBank under

Table 2 PCR primers used in this study

\begin{tabular}{|c|c|c|c|c|}
\hline Primer & Sense & Species & Sequence $\left(5^{\prime} \rightarrow 3^{\prime}\right)$ & Gene location \\
\hline RecApp-F & Forward & P. parvulus and & CAAATTGCAACGATGCCTACTGGATCC & Recombinase A \\
\hline RecApp-R & Reverse & P. damnosus & GGTGCCATCCTTAATCTGTTCCGCCCG & \\
\hline RplBoo-F & Forward & P. parvulus and & GGTCGTATGACTGTTCGCCATCATGGTGGTGG & Ribosomal protein L2 \\
\hline RplBoo-R & Reverse & P. damnosus & GGGTTCATAACAGAACCACGAACATGTGGA & \\
\hline PyrGppento-F & Forward & P. parvulus and & GGAATGAATCATTCCTTCAATCCCACG & CTP synthase \\
\hline PyrBppento-R & Reverse & P. damnosus & AAATATATTTTTGTTACAGGTGGGGTTGTTT & \\
\hline LeuSoo-F & Forward & P. parvulus and & GCAGGTTAAATCACTTGGTTTTTCTTATGACTGG & Leucyl-tRNA synthase \\
\hline LeuSoo-R & Reverse & P. damnosus & TCACGCGTATCATGAGCTGGAACAGCCAT & \\
\hline Mlepar-F & Forward & P. parvulus & CGATCGCCGACACCATCGAAAATTACAGTG & Malolactic enzyme \\
\hline Mlepar-R & Reverse & & TGTGGTGATTTGGTCCTTATACTTATTCAAGATATTAGC & \\
\hline Mledam-F & Forward & P. damnosus & CCATTGCCGACACAATTGAAAACTATAGTGA & Malolactic enzyme \\
\hline Mledam-R & Reverse & & TGTCGTGATTTTGTCTTTGTACGTATTTAAGATATTAGC & \\
\hline RecA-ST3-F & Forward & P. parvulus ST3 & GGATCCTTAGCACTAGATGAC & Recombinase A \\
\hline RecA-ST3-R & Reverse & & AATGTTAACCCCTAAGTGTTCA & \\
\hline RecA-ST2-F & Forward & P. parvulus ST2 & GGATCCTTAGCACTAGATGAT & Recombinase A \\
\hline RecA-ST2-R & Reverse & & AATGTTAACCCCTAGGTGTTCC & \\
\hline
\end{tabular}


the accession numbers EU331244-EU331291 (P. parvulus) and EU331292-EU331357 (P. damnosus).

\section{DNA Sequence Analysis}

The resulting sequences, augmented of the GenBank accession CP000422, were imported into the Seaview software package [27] and manually aligned according to the alignment of amino acid sequences originating from translated DNA sequences. Alignments were trimmed to a uniform length (corresponding to nucleotide positions 3341010 for leuS, 80-1022 for $p y r G, 111-694$ for $r e c A, 148-671$ for $r p l B$ and 291-760 for mle of the genome of Pediococcus pentosaceus ATCC 25745 (Acc. No. CP000422)). The trimmed alignments were also used to construct a concatenated alignment. Trees based on the neighbour-joining method were built from the individual alignments as well as from the concatenated alignment. Reliability of the tree structure was assessed via bootstrap analysis, using the PhyML program [28] according to Belbahri et al. [29].

\section{Primer Design and Real Time PCR Analysis}

Primers specific to the strains Bpe 149 and Bpe 184 were developed through visual comparison of the alignment of all sequences used for the phylogenetic analysis of the recA gene (Table 2). Primers were specifically designed to discriminate not only between both strains but also among closely related lab Cocci such as $P$. pentosaceus, $P$. damnosus and $P$. dextrinicus and other wine bacteria, particularly those widely represented such as Oenococcus oeni. The specificity of potential primers was further tested by BLAST [30] searching GenBank for compatible sequences. Following the identification of suitable target regions in the allelic sequences of the recA gene of $P$. parvulus Bpe 149 and Bpe 184 strains, primers were tested against putative crosshybridizing species listed above. Amplifications were carried out in capped capillary tubes in a Lightcycler 2.0 Real Time PCR systems (Roche Diagnostics, Rotkreuz, Switzerland) using an initial denaturation at $95^{\circ} \mathrm{C}$ for $10 \mathrm{~min}$, followed by 60 cycles of $95^{\circ} \mathrm{C}$ for $10 \mathrm{~s}, 68^{\circ} \mathrm{C}$ for $10 \mathrm{~s}$ and $72^{\circ} \mathrm{C}$ for $7 \mathrm{~s}$. Amplification mixtures ( $20 \mu \mathrm{l}$ final volume) were built with the Light Cycler Fast Start DNA Master SYBR Green I kit added of 2 ng of template DNA and primers at a final concentration of $0.5 \mu \mathrm{M}$.

\section{Results}

16S rDNA Strains Identification

As shown by $16 \mathrm{~S}$ rDNA amplification and sequencing, seven strains belonged to P. damnosus and 10 to P. parvulus.
Another strain (not shown here) belonged to Oenococcus oeni and was thus discarded.

Selection and Characteristics of MLST Marker Genes

General criteria for MLST marker gene selection included (i) the genes have to be preferably interspaced across the entire genome based on LAB bacteria complete genome sequences available [31], (ii) the functions of the encoded proteins, preferably conserved and well characterized and iii) presence of the selected genes in all the strains as a single copy of a minimum size of $1 \mathrm{~kb}$ allowing PCR primer design. The mle gene was selected based on the results of previous studies on Oenococcus oeni and other LAB bacteria [18, 23]. Selection of the remaining loci (recA, $r p l B$, pyrG and leuS) was based on a preliminary analysis of several housekeeping genes ( $g y r B, r e c A, r p o B$, $r p l B, r e c G, p y r G$, leuS and mle and the 16S rRNA) with degenerated universal primers (data not shown). This preliminary study showed that $r e c A, r p l B, p y r G$ and leuS displayed sufficient sequence diversity among $P$. parvulus and $P$. damnosus strains investigated, providing the best phylogenetic resolution amongst the genes tested.

\section{Comparative Sequence Analyses}

Pediococcus parvulus sequences were registered under the following GenBank accessions: EU331244-EU331251 for $r p l B, \quad$ EU331252-EU331259 for 16S rRNA gene, EU331260-EU331267 for leuS, EU331268-EU331275 for mle, EU331276-EU331283 for pyrG, EU331284EU331291 for recA. Pediococcus damnosus sequences were registered under the following GenBank accessions: EU331292-EU331302 for rplB, EU331303-EU331313 for 16S rRNA gene, EU331314-EU331324 for leuS, EU331325-EU331335 for mle, EU331336-EU331346 for pyrG, EU331347-EU331357 for recA.

The characteristics of the marker genes are summarized in Table 3. Individual marker genes allowed for the discrimination of up to three distinct allelic types, differentiated by at least one nucleotide difference (Fig. 1). Sequence variation was low and ranged, for instance, from 0 to $2.67 \%$, for $P$. parvulus with the $r p l B$ gene. For $P$. damnosus all the genes analysed displayed very little sequence variability (Table 3 ). The genes $r p l b, m l e, r e c A$ and $\operatorname{pyr} G$ proved to be suitable markers for $P$. parvulus strain level differentiation with 2, 2, 3 and 3 alleles, respectively (Fig. 1), in the collection of the nine strains analysed (Table 3). The 11 P. damnosus strains displayed a variability reduced to a unique polymorphic site within the $r p l B$, leuS and mle genes, with 2, 2 and 2 alleles, respectively (Fig. 1). The gene leuS displayed no variability in all 
Table 3 Characteristics of the marker genes used in this study

\begin{tabular}{|c|c|c|c|c|c|c|}
\hline Species & Gene & $\begin{array}{l}\text { Size for } \\
\text { analysis (bp) }\end{array}$ & $\mathrm{G}+\mathrm{C}(\%)$ & No. of alleles & $\begin{array}{l}\text { No. of sequences } \\
\text { analysed }\end{array}$ & $\begin{array}{l}\text { No. of } \\
\text { polymorphic sites }\end{array}$ \\
\hline \multirow[t]{5}{*}{ P. parvulus } & recA & 584 & 43 & 3 & 8 & 4 \\
\hline & rplB & 524 & 40.6 & 2 & 8 & 14 \\
\hline & pyrG & 943 & 38.5 & 3 & 8 & 2 \\
\hline & leuS & 677 & 43 & 1 & 8 & 0 \\
\hline & mle & 470 & 40.2 & 2 & 8 & 8 \\
\hline \multirow[t]{5}{*}{ P. damnosus } & recA & 584 & 42.8 & 1 & 11 & 0 \\
\hline & rplB & 524 & 42.1 & 2 & 11 & 1 \\
\hline & pyrG & 943 & 38.3 & 1 & 11 & 0 \\
\hline & leuS & 677 & 41.1 & 2 & 11 & 1 \\
\hline & mle & 470 & 40.2 & 2 & 11 & 1 \\
\hline
\end{tabular}

Fig. 1 Polymorphic nucleotide sites in $P$. parvulus and $P$. damnosus MLST genes. Only the variable sites are shown. The nucleotide at each site is shown for a putative consensus sequence; only those that differ from the nucleotide in the consensus sequence are shown for the alleles. Nucleotide sites are numbered in a vertical format from the first nucleotide position of the considered gene. The number of strains harbouring the allele is indicated in brackets

\section{P. parvulus}

$\begin{array}{rcccccc} & 2 & 7 & 1 & 2 & 3 & 3 \\ & 6 & 6 & 4 & 0 & 0 & 1 \\ & 7 & 1 & 4 & 4 & 9 & 6 \\ \text { Consensus } & \text { G } & \text { C } & \text { T } & \text { C } & \text { A } & \text { C } \\ \text { ST1 (3) } & . & . & . & . & . & . \\ \text { ST2 (1) } & . & . & . & . & \text { G } & . \\ \text { ST3 (2) } & \text { A } & . & \text { C } & \text { T } & \text { T } & \text { T } \\ \text { ST4 (2) } & . & \text { T } & . & . & . & . \\ & \text { pyrG } & & & & & \text { recA }\end{array}$

\section{P. damnosus}

$\begin{array}{rccc} & 6 & 3 & 5 \\ & 6 & 9 & 5 \\ & 6 & 0 & 1 \\ \text { Consensus } & \text { C } & \text { A } & \text { T } \\ \text { ST1 (6) } & \cdot & \cdot & \cdot \\ \text { ST2(3) } & \text { A } & \cdot & \cdot \\ \text { ST3(2) } & \cdot & \text { G } & \text { C } \\ & \text { leuS } & \text { rplB } & \text { mle }\end{array}$

strains $P$. parvulus while recA and pyrG displayed no variability in all strains of $P$. damnosus (Fig. 1, Table 3).

\section{MLST Differentiation of Pediococcus Strains}

Based on the recA, rplB, pyrG, leuS and mle, 4 and 3 sequence types (ST) could be identified amongst the 8 $P$. parvulus and $11 P$. damnosus isolates respectively (Table 1, Fig. 1), corresponding to a discriminatory ability of $1 \mathrm{ST}$ for 2 isolates of $P$. parvulus and $1 \mathrm{ST}$ for 3.6 isolates. While none of the individual marker genes allowed for the identification of at least a majority of the isolates analysed, their combination provided a resolution well beyond that level (Fig. 2). P. parvulus strain Bpe 299 matched the strain CBS 20332. Similarly P. damnosus strain Bpe 294 matched the reference strain CBS 20331 (Fig. 2).
Primer Design and Real Time PCR Analysis

The PCR primer pair (RecA-149-F, RecA-149-R) produced a single band approximately $207 \mathrm{bp}$ in size for $P$. parvulus ST2 (Bpe 149). At the highest temperature where amplification was still possible $\left(66^{\circ} \mathrm{C}\right)$ no bands were produced when the primers were tested against genomic DNA from all closely related STS such as ST3 (illustrated by strain Bpe 301 in Fig. 3) and species i.e. P. damnosus, P. dextrinicus and Oenococcus mesenteroides. The primer pair (RecA-184-F, RecA-184-R) produced a single band approximately $207 \mathrm{bp}$ in size for $P$. parvulus ST3 (illustrated by strain Bpe 301 in Fig. 4). At the highest annealing temperature allowing amplification $\left(66^{\circ} \mathrm{C}\right)$, no cross amplification was observed with ST2 (strain Bpe 149, Fig. 4) as well as closely related species $P$. damnosus, 
Fig. 2 Neighbour-joining dendrogramme based on concatenated nucleotide sequences of the recA, rplB, pyrG, leuS and mle genes. The positions considered to generate the tree are shown in Fig. 1.

Bootstrap values higher than $50 \%$ from 100 replicates are shown. The bar represents $1 \%$ evolutionary sequence divergence

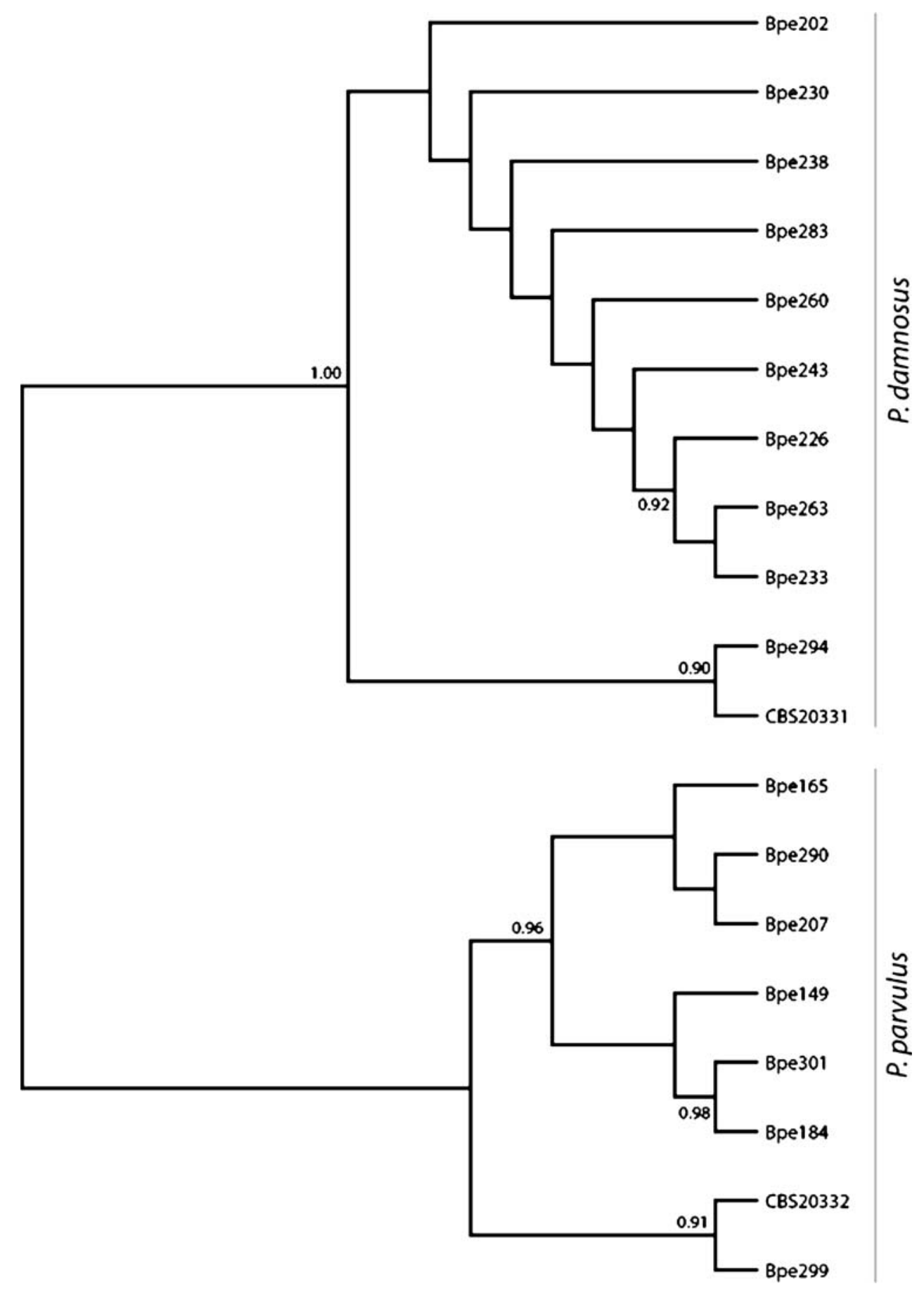

P. dextrinicus and Oenococcus mesenteroides (Fig. 4). In Real Time PCR similar results have been obtained except that some cross amplification was observed when using primer pair (RecA-149-F, RecA-149-R) against ST3 (illustrated by strain Bpe 301 in Fig. 3). However melting curve analysis could easily be used to rule out misunderstanding of the amplification observed, and under gel electrophoresis analysis the amplicon seems to correspond to a non-specific product of higher size (Fig. 3).

\section{Discussion}

Identification of strains belonging to the same species is still difficult to achieve in LAB such as the genus Pediococcus. This is mainly due to difficulties in morphological identification based on phenotypic features and biochemical traits highly dependent on physiological state of cells. Suitable and highly precise Pediococcus typing techniques are not available. A reproducible, 
(a) $\begin{array}{lllllllll}55.0 & 55.3 & 56.5 & 58.2 & 60.5 & 63.1 & 65.8 & 68.5 & { }^{\circ} \mathrm{C}\end{array}$
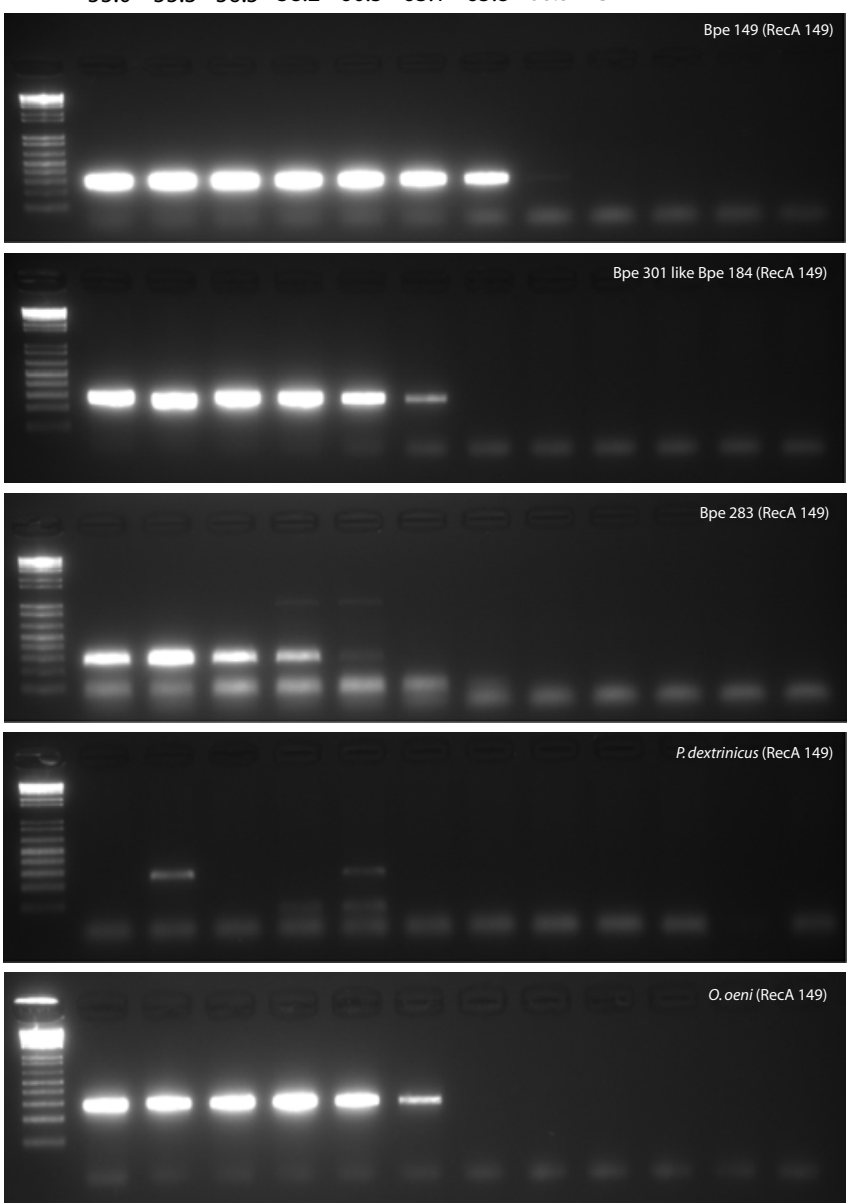

Fig. 3 Reaction of strains Bpe 149, Bpe 301, Bpe 283, P. dextrinicus and Oenococcus oeni to the PCR primer pairs RecA-149-F and RecA149-R. (a) Specificity of the primer pairs RecA-149-F and RecA-149$\mathrm{R}$ at different annealing temperatures with DNA from respective strains listed above. Annealing temperatures ranging between 55 and

cheap, fast and error-free method with a higher resolution than conventional identification schemes would be a priority for the biotechnological applications of these bacteria.

Multi-loci sequence typing (MLST) tends to be the preferred method in molecular typing of LAB bacteria and has been applied successfully to Lactococcus casei, Oenococcus oeni, Lactobacillus plantarum and Pediococcus acidilactici [17-20]. The existing MLST schemes were based on housekeeping genes. In this study the combination of recA, rplB, leuS, pyr housekeeping genes and the malolactic enzyme gene mle conveniently grouped $P$. parvulus and $P$. damnosus strains into groups corresponding to recognised species (Fig. 1). Besides that, the most widely used phylogenetic marker, the 16S rDNA gene displayed very little sequence variability within the (b)
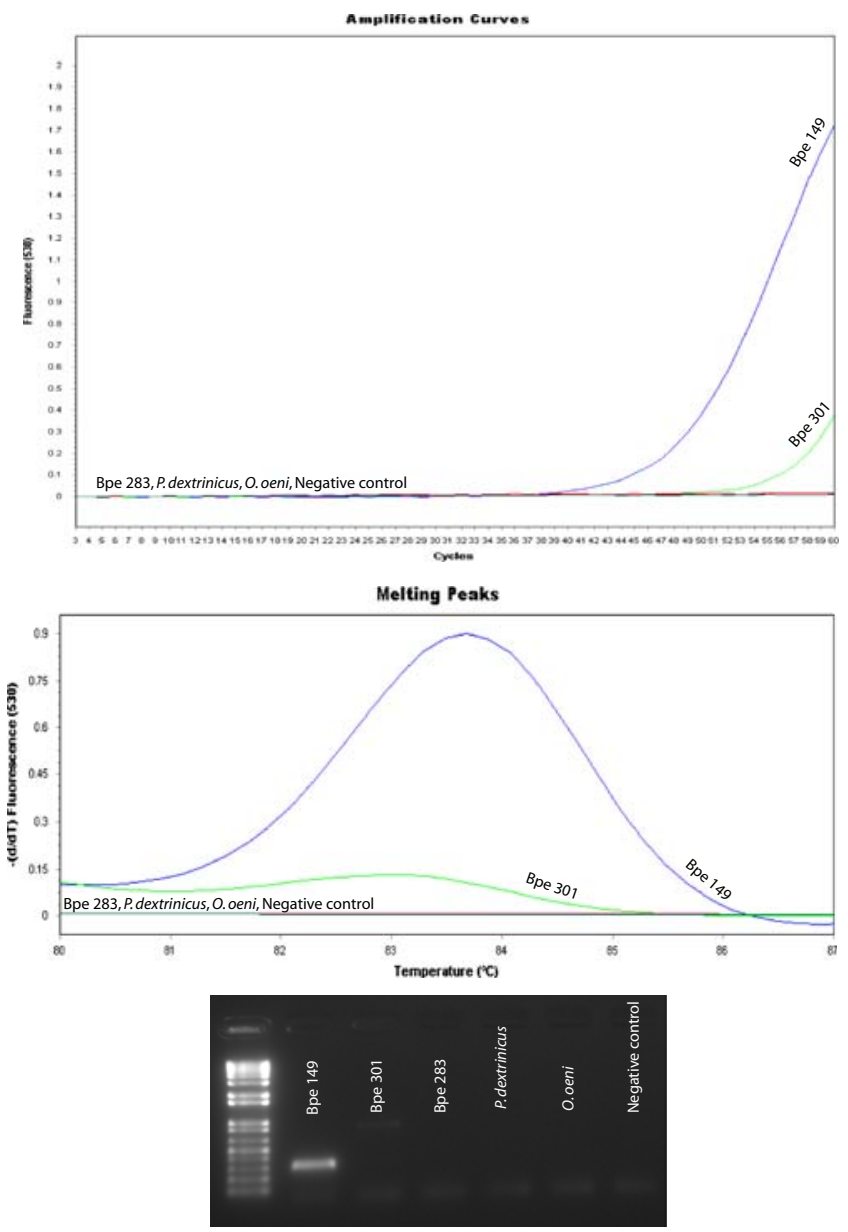

$75^{\circ} \mathrm{C}$ are indicated in the figure. (b) Specificity of the primer pairs RecA-149-F and RecA-149-R in real time experiments. Amplification curves, Melting peaks analysis and agarose gel electrophoresis of amplification products are shown

two Pediococcus species investigated. The number of alleles of the 4 housekeeping and the mle genes ranged from 1 to 3 (Table 1). Sequence variation ranged from 0 to $2.67 \%$, for $P$. parvulus with the $r p l B$ gene. The obtained variability was low, in comparison to those observed in other studies using MLST on related LAB (0.3-6.6\% for Oenococcus oeni [18], 1-7.7\% in Lactobacillus plantarum [19] and 1.4-7.8\% [17], lab cocci [17, 18]. This could be explained by the fact that strains of the present study were collected from the same fermentation experiment in the same location. Surprisingly a strain of P. parvulus, Bpe299 was similar to the CBS20332 strain and they shared the ST4 type which was the rarest type among these isolates. This ST4 type diverged fairly from the consensus sequence obtained form these local strains. These strains were however identified without any 
(a)

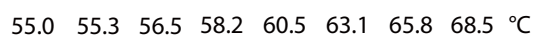
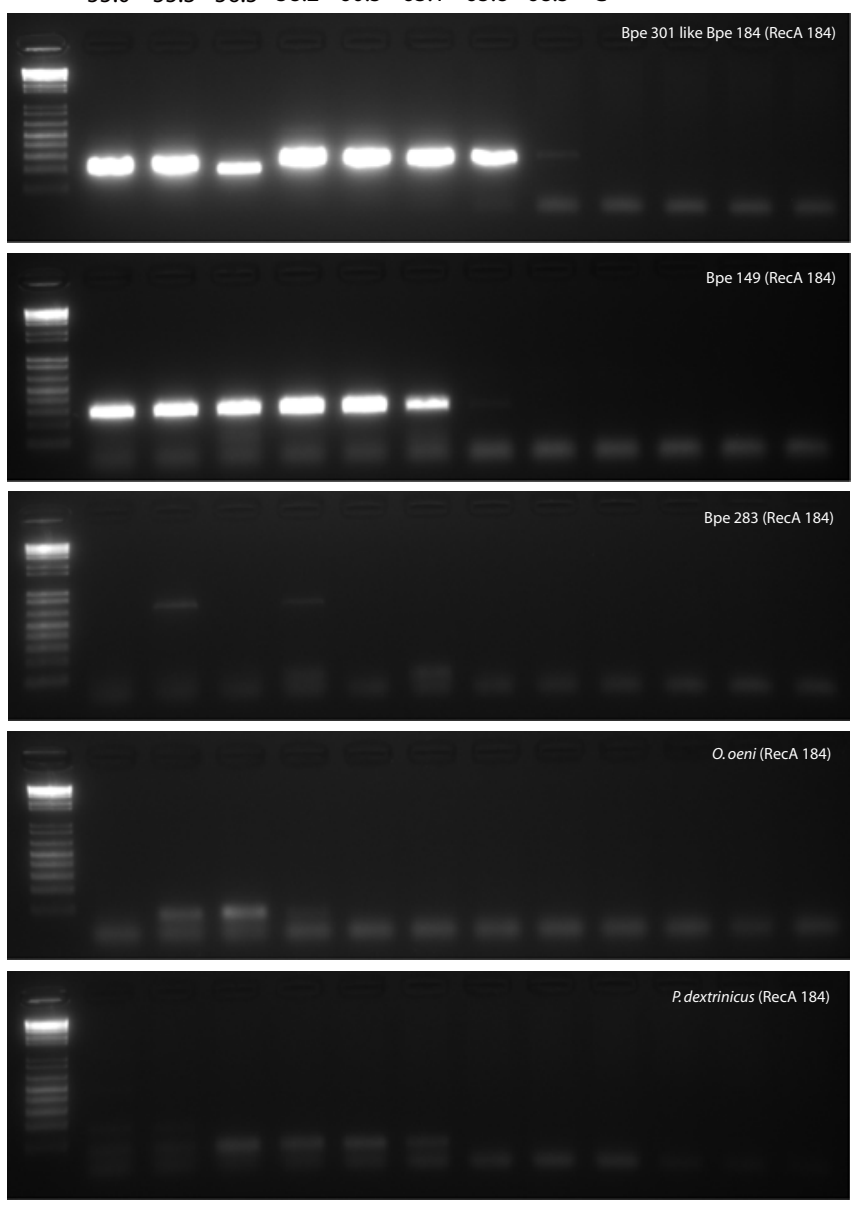

Fig. 4 Reaction of strains Bpe 301, Bpe 149, Bpe 283, P. dextrinicus and Oenococcus oeni to the PCR primer pairs RecA-184-F and RecA184-R. (a) Specificity of the primer pairs RecA-184-F and RecA-184$\mathrm{R}$ at different annealing temperatures with DNA from respective strains listed above. Annealing temperatures ranging between 55 and

ambiguity as $P$. parvulus by the $16 \mathrm{~S}$ rDNA sequence; consequently this variation could originate from recombination events or horizontal gene transfer between compatible bacteria species. A comprehensive sequence database would be required in order to maximize the full potential of molecular methods for P. parvulus and $P$. damnosus typing. The recA, rplB, pyrG, leuS and mle sequences obtained from 8 P.parvulus and 11 $P$. damnosus isolates showed substantial intra-species phylogenetic variation, indicating a strong typing potential. While the selected isolates could be considered as local isolates, sequence data from other countries, from other geographical regions of Switzerland and neighbour countries, would most likely further broaden the known diversity. Establishing such a comprehensive sequence database would also shed light onto the evolution of LAB cocci P. parvulus and P. damnosus and allow for their (b)
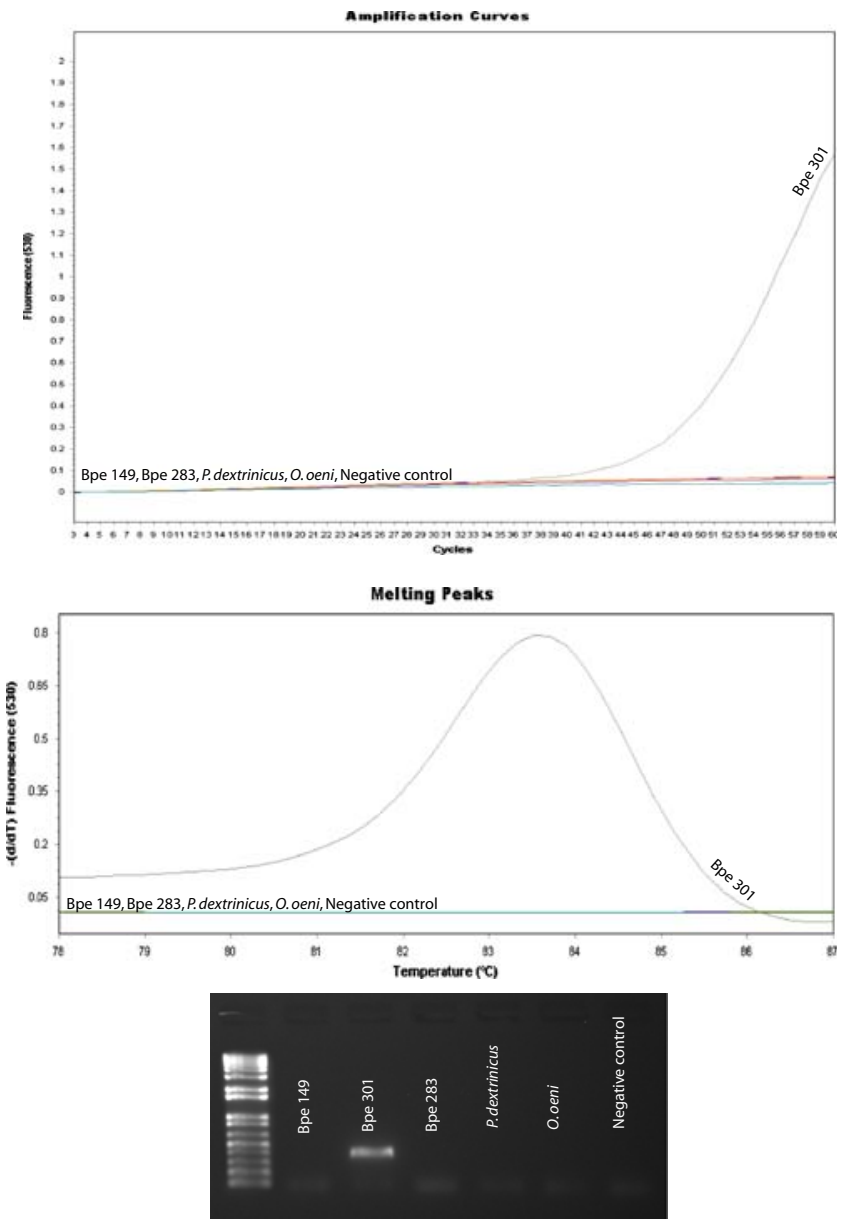

$75^{\circ} \mathrm{C}$ are indicated in the figure. (b) Specificity of the primer pairs RecA-184-F and RecA-184-R in real time experiments. Amplification curves, melting peaks analysis and agarose gel electrophoresis of amplification products are shown

large-scale characterization. The combination of all five marker genes would be required for a reliable typing of all the isolates, taking into consideration potential minor sequence variations.

Meanwhile our study showed unambiguously that MLST could provide with a resolution at the infra-specific level. The existing variability was sufficient for designing primers that allowed for the detection of a specific ST of the species P. parvulus in PCR and Real Time PCR experiments (Figs. 3 and 4). This type of studies is highly suited in numerous biotechnological applications such as identification and monitoring of specific wine spoilage bacteria during fermentation experiments, for which these protocols are being validated with LAB mixes (data not shown). Other applications could include strain characterization prior to patent and release of a valuable $\mathrm{LAB}$ species for commercial applications [19]. 


\section{Conclusions}

The combination of housekeeping genes $r e c A, r p l B$, pyrG, $l e u S$ and the malolactic enzyme encoding gene mle showed good discrimination amongst the $P$. parvulus and the $P$. damnosus strains investigated. These results indicate that the approach enabled efficient molecular typing for the closely related $P$. parvulus and $P$. damnosus species as well as an intra-species resolution. Taking advantage of the sequence differences, we could design isolate specific PCR primers that proved effective in detecting without ambiguity a specific strain of $P$. parvulus and $P$. damnosus. The primers proved also effective in Real Time experiments allowing fast and reliable identification of these wine spoilage bacteria.

Acknowledgements This work was financially supported by the Strategic Reserve Fund Realtech of the University of Applied Sciences of Western Switzerland (Project Number 17435) and the Research Fund of the School of Engineering of Lullier, University of Applied Sciences of Western Switzerland. Bacterial isolates were kindly provided by Serge Hautier, School of Engineering of Changins, University of Applied Sciences of Western Switzerland Route de Duillier, 1260 Nyon, Switzerland.

\section{References}

1. Fleet, G. H. (1997). The microbiology of alcoholic beverages. In B. J. B. Wood (Ed.), Microbiology of fermented foods (Vol. 1, 2nd edn.). Blackie Academic \& Professional, pp. 217-262.

2. Lopez, I., Ruiz-Larrea, F., Cocolin, L., Orr, E., Phister, T., Marshall, M., et al. (2003). Design and evaluation of PCR primers for analysis of bacterial populations in wine by denaturing gradient gel electrophoresis. Applied and Environmental Microbiology, 69, 6801-6807. doi:10.1128/AEM.69.11.6801-6807.2003.

3. Lonvaud-Funel, A. (1999). Lactic acid bacteria in the quality improvement and depreciation of wine. Antonie Van Leeuwenhoek International Journal of General and Molecular Microbiology, 76, 317-331. doi:10.1023/A:1002088931106.

4. Ribereau-Gayon, P. (2000). Handbook of enology. Chichester, United Kingdom: Wiley.

5. Davis, C. R., Wibowo, D., Eschenbruch, R., Lee, T. H., \& Fleet, G. H. (1985). Practical implications of malolactic fermentation: A review. American Journal of Enology and Viticulture, 36, 290-301.

6. Manca de Nadra, M., \& Strasser de Saad, A. (1995). Polysaccharide production by Pediococcus pentosaceus from wine. International Journal of Food Microbiology, 27, 101-106. doi: 10.1016/0168-1605(94)00118-P.

7. Osborne, J. P., Mira de Orduna, R., Pilone, G. J., \& Liu, S. Q. (2000). Acetaldehyde metabolism by wine lactic acid bacteria. FEMS Microbiology Letters, 191, 51-55. doi:10.1111/j.15746968.2000.tb09318.x.

8. Coton, E., Rollan, G., Bertrand, A., \& Lonvaud-Funel, A. (1998). Histamine-producing lactic acid bacteria in wines: Early detection, frequency, and distribution. American Journal of Enology and Viticulture, 49, 199-204.

9. Renouf, V., Claisse, O., \& Lonvaud-Funel, A. (2006). rpoB gene: A target for identification of LAB cocci by PCR-DGGE and melting curves analyses in Real Time PCR. Journal of
Microbiological Methods, 67, 162-170. doi:10.1016/j.mimet. 2006.03.008.

10. Claisse, O., Renouf, V., \& Lonvaud-Funel, A. (2007). Differentiation of wine lactic acid bacteria species based on RFLP analysis of a partial sequence of rpoB gene. Journal of Microbiological Methods, 69, 387-390. doi:10.1016/j.mimet.2007.01.004.

11. Renouf, V., Claisse, O., \& Lonvaud-Funel, A. (2007). Inventory and monitoring of wine microbial consortia. Applied Microbiology and Biotechnology, 75, 149-164. doi:10.1007/s00253-006-0798-3.

12. Lafon-Lafourcade, S., \& Joyeux, A. (1979). Techniques simplifiées pour le dénombrement et l'identification des microorganismes vivants dans les moûts et les vins. Conn. Vigne Vin, 13, 295-310.

13. Santos, E. M., Jaime, I., Rovira, J., Lyhs, U., Korkeala, H., \& Bjorkroth, J. (2005). Characterization and identification of lactic acid bacteria in "morcilla de Burgos". International Journal of Food Microbiology, 97, 285-296. doi:10.1016/j.ijfoodmicro. 2004.04.021.

14. Rantsiou, K., Comi, G., \& Cocolin, L. (2004). The rpoB gene as a target for PCR-DGGE analysis to follow lactic acid bacterial population dynamics during food fermentations. Food Microbiology, 21, 481-487. doi:10.1016/j.fm.2003.10.002.

15. Tamang, B., Tamang, J. P., Schillinger, U., Franz, C. M., Gores, M., \& Holzapfel, W. H. (2007). Phenotypic and genotypic identification of lactic acid bacteria isolated from ethnic fermented bamboo tender shoots of North East India. International Journal of Food Microbiology, 121, 35-40.

16. Plengvidhya, V., Breidt, F., Jr, Lu, Z., \& Fleming, H. P. (2007). DNA fingerprinting of lactic Acid bacteria in sauerkraut fermentations 1. Applied and Environmental Microbiology, 73(23), 7697-7702. doi:10.1128/AEM.01342-07.

17. Cai, H., Rodriguez, B. T., Zhang, W., Broadbent, J. R., \& Steele, J. L. (2007). Genotypic and phenotypic characterization of Lactobacillus casei strains isolated from different ecological niches suggests frequent recombination and niche specificity. Microbiology-Sgm, 153, 2655-2665. doi:10.1099/mic.0.2007/006452-0.

18. de las Rivas, B., Marcobal, A., \& Munoz, R. (2004). Allelic diversity and population structure in Oenococcus oeni as determined from sequence analysis of housekeeping genes. Applied and Environmental Microbiology, 70, 7210-7219. doi:10.1128/ AEM.70.12.7210-7219.2004

19. de las Rivas, B., Marcobal, A., \& Muñoz, R., (2006). Development of a multilocus sequence typing method for analysis of Lactobacillus plantarum strains. Microbiology, 152, 85-93. doi: 10.1099/mic.0.28482-0.

20. Mora, D., Fortina, M. G., Parini, C., Daffonchio, D., \& Manachini, P. L. (2000). Genomic subpopulations within the species Pediococcus acidilactici detected by multilocus typing analysis: Relationships between pediocin AcH/PA-1 producing and nonproducing strains. Microbiology-Sgm, 146, 2027-2038.

21. Rodas, A. M., Ferrer, S., \& Pardo, I. (2003). 16S-ARDRA, a tool for identification of lactic acid bacteria isolated from grape must and wine. Systematic and Applied Microbiology, 26, 412-442. doi:10.1078/072320203322497446.

22. Chenoll, E., Macian, M. C., \& Aznar, R. (2003). Identification of Carnobacterium, Lactobacillus, Oenococcus and Pediococcus by rDNA-based techniques. Systematic and Applied Microbiology, 26, 546-556. doi:10.1078/072320203770865855.

23. Groisillier, A., \& Lonvaud-Funel, A. (1999). Comparison of partial malolactic enzyme gene sequences for phylogenetic analysis of some lactic acid bacteria species and relationships with the malic enzyme. International Journal of Systematic Bacteriology, 49, 1417-1428.

24. Maiden, M. C. J., Bygraves, J. A., Feil, E., Morelli, G., Russell, J. E., Urwin, R., et al. (1998). Multilocus sequence typing: A portable approach to the identification of clones within 
populations of pathogenic microorganisms. Proceedings of the National Academy of Sciences of the United States of America, 95, 3140-3145. doi:10.1073/pnas.95.6.3140.

25. Weisburg, W. G., Barns, S. M., Pelletier, D. A., \& Lane, D. J. (1991). 16S ribosomal DNA amplification for phylogenetic study. Journal of Bacteriology, 173(2), 697-703.

26. Santos, S. R., \& Ochman, H. (2004). Identification and phylogenetic sorting of bacterial lineages with universally conserved genes and proteins. Environmental Microbiology, 6(7), 754-759. doi:10.1111/j.1462-2920.2004.00617.x.

27. Galtier, N., Gouy, M., \& Gautier, C. (1996). SEAVIEW and PHYLO_WIN: Two graphic tools for sequence alignment and molecular phylogeny. Computer Applications in the Biosciences, $12,543-548$.

28. Guindon, S., \& Gascuel, O. (2003). A simple, fast, and accurate algorithm to estimate large phylogenies by maximum likelihood.
Systematic Biology, 52, 696-704. doi:10.1080/10635150390 235520.

29. Belbahri, L., Moralejo, E., Calmin, G., Oszako, T., Garcia, J. A., Descals, E., et al. (2006). Phytophthora polonica, a new species isolated from declining Alnus glutinosa stands in Poland. FEMS Microbiology Letters, 261, 165-174. doi:10.1111/j.1574-6968. 2006.00349.x.

30. Altschul, S. F., Madden, T. L., Schaffer, A. A., Zhang, J. H., Zhang, Z., Miller, W., et al. (1997). Gapped BLAST and PSI-BLAST: A new generation of protein database search programs. Nucleic Acids Research, 25, 3389-3402. doi:10.1093/nar/25.17.3389.

31. Makarova, K., Slesarev, A., Wolf, Y., Sorokin, A., Mirkin, B., Koonin, E., et al. (2006). Comparative genomics of lactic acid bacteria. Proceedings of the National Academy of Sciences of the United States of America, 103, 15611-15616. doi:10.1073/ pnas.0607117103. 